\title{
Analyzing Remanufacturability of Mobile Phones using DEMATEL Approach
}

\author{
Gan Shu San ${ }^{1 *}$
}

\begin{abstract}
The use of mobile phone has increased at a surprisingly high rate over these two decades. For many people, especially young generations, mobile phone has even become a primary need. As a consequence, the production of mobile phone has increased significantly and followed immediately by the disposal, as a result of its short life-cycle nature. Recently, there are substantial initiatives proposed in order to mitigate the effect of e-waste to the environment. Remanufacturing is one of recovery processes that could extend product's useful life and provide a circular life-cycle instead of linear. However, there are many factors that can affect the success of remanufacturing engagement, and specifically remanufacturability of a mobile phone. There are numerous considerations of remanufacturability with regards to the short life-cycle nature of mobile phone, and these factors can be qualitative or quantitative, with conflicting potentials, and some of them may be uncertain. In this study, we use Decision Making Trial and Evaluation Laboratory (DEMATEL) approach to identify the interrelationship among the factors and analyze those results to identify the prominent factors. Furthermore, an influential-relation map is provided to support visualization for managerial implications. The case results show that innovation-rate and obsolescence are factors that give highest impact while source-of-returns and pricing are factors that receive highest effects from other factors. Also, acquisition-of-usedproduct, pricing, and market-size are dominant factors as they significantly affect and affected by others.
\end{abstract}

Keywords: Remanufacturing; mobile phone; influential-relation map; DEMATEL.

\section{Introduction}

The use of mobile phone has increased at a surprisingly high rate over these two decades. A study shows that smartphone users are increasing from 1.31 billion in 2013 to 1.64 billion in 2014 (EMarketer [1]). For many people, especially young generations, mobile phone has even become a primary need. As a consequence, the production of mobile phone has increased significantly which means increased consumption of raw materials from natural resources, such as energy and metal. It is also followed immediately by disposal mobile phone that has reached its end-of-use or end-of-life, as a result of its short life-cycle nature. Recently, there are substantial initiatives proposed in order to mitigate the effect of e-waste to the environment. Remanufacturing is one of recovery processes that could extend product's useful life, and provide a circular life-cycle instead of linear (van Weelden et al. [2]). However, there are many factors that could affect the success of remanufacturing engagement, such as remanufacturing feasibility (Goodall et al. [3]), and specifically remanufacturability of a mobile phone.

1 Faculty of Industrial Technology, Mechanical Engineering Department, Petra Christian University, Л. Siwalankerto 121-131, Surabaya, 60238, Indonesia

Email: gshusan@petra.ac.id

* Corresponding author
In the early implementation of remanufacturing, only durable product with stable technology is considered suitable for remanufacturing (Ferguson and Souza [4], Lebreton and Tuma [5], Charter, and Gray [6], Östlin et al. [7]). In the development, the scope of remanufacturing is getting broader that covers short life cycle products. Several studies show that remanufacturing of electronic products and mobile phones has good potential (Franke et al. [8], Tong [9], Rathore et al. [10]) and profitable (Xing et al.[11], Kwak and Kim [12]). Franke et al. [8] claim that successful remanufacturing of electric and electronic products, including mobile phone, should consider the nature of short-lifecycle product, product design that is not prepared for remanufacturing, and labor cost in high-wage countries. Wassenhove and Zikopoulos [13] study the effect of grading and classification of returned product and use the case of ReCellular, a mobile phone remanufacturer. The results show that classification accuracy is important to secure profitability. Nnorom and Osibanjo [14] explore the prospect of adopting remanufacturing for electronic product, and use remanufacturing operation of a mobile phone as illustration. They find that product design and product obsolescence should be addressed accordingly. Rathore et al. [10] investigate the market demand, whether remanufactured mobile phone would be accepted by customers. Neto and Bloemhof [15] study the effectiveness and ecoefficiency of remanufacturing in personal computer and mobile phone industries. They find that WTP of 
remanufactured product, and consequently their ecoefficiency, are dependent on price of its new product counterpart at launch and the time between new product launch and remanufacturing. Also, the sale price of remanufactured product is lower relative to the new one. Focusing on circular consumption, van Weelden et al. [2] investigate Dutch market's acceptance of refurbished mobile phone. The results show that the level of awareness and understanding of refurbished product is low, and there is negative trade-off between perceived risks and benefits. Mugge et al. [16] show that customers' purchase intention for refurbished smartphone is positively influenced by perceived environmental benefits and awareness of refurbishing. Furthermore, the driver for purchasing are product related, such as upgraded performance, guaranteed software updates. Phantratanamongkol et al. [17] study the price-volume relationship for new and remanufactured smartphones via online channel i.e. eBay UK and eBay US. The results show that remanufactured smartphones have higher potential for profitability, which show the importance of choosing the right market channel. Gurita et al. [18] shows that the potential for reuse/remanufacturing mobile phone and smartphone is quite high in Germany market, but there are challenges in low collection rate and customers' attitude towards remanufactured mobile phone.

The above studies show that there are numerous considerations of remanufacturability with regards to the short life-cycle nature of mobile phone, and these factors can be qualitative or quantitative, with conflicting potentials, and some of them may be uncertain. Therefore, it is important to analyze these factors to find prominent factors and interrelationship among factors. Several studies have been conducted to analyze factors that influence remanufaturability, but not for short life-cycle product, but rather for automotive sector (D'Adamo and Rosa [19], Chaowanapong [20], Xia et al. [21]) or for general industry (Goodall et al. [3], Bhatia and Srivastava [22], Sharma et al. [23], Wei et al. [24]). This paper aims to explore factors that influence the remanufacturability of mobile phone and analyze those factors using DEMATEL approach, which will be useful for manufacturer in making decision to engage in remanufacturing. This approach is selected because DEMATEL is considered as an effective approach to identify all intertwined cause-effect of many factors, as occurred in this problem.

\section{Methods}

\section{Decision Criteria for Remanufacturability of Mobile Phone}

There are numerous studies that discuss factors that influence remanufacturability of a product. Based on a literature review, factors that are relevant to short life-cycle products, especially mobile phone, are collected. We also expand our literature study to include the specific characteristics of remanufacturing a short life-cycle product. The factors are then categorized into four groups, consistent with Gan et al. [25,26], which are:

\section{Product Characteristics}

Mobile phone is typically a short life-cycle product which has specific characteristics due to its fastobsolete nature. Remanufacturability of such product is influenced by how fast the technology innovation is. The faster the technology changes the lower viability for remanufacturing (Ferguson and Souza [4], Souza [27]). Product with short life-cycle is also susceptible to the duration of use by the first customer, which is labelled as residence time (Debo et al. [28]), before it is collected as a core for recovery process. The longer the residence time, the lower the potential for successful remanufacturing (Debo et al. [29]). Used product often retain residual value even after reaching its end-of-use. The lower the residual value, the higher opportunity for voluntary take back even in the absence of legal regulation (Franke et al. [8]). On the other hand, high residual value is associated with first-class recovery option such as remanufacturing (Gobbi [30]) and serves as enabler for remanufacturing operation (Chakraborty [31]). Technology obsolescence also plays an important role in remanufacturing (Nnorom and Osibanjo [14]). Customers are concerned about the risk of mobile phone being obsolete quickly (Bhatia and Srivastava [22], Deshpande [32]) and fast emerging new models can drive the obsolescence even faster (Gurita [18]). From the above discussion, we derive four factors i.e.

F1: Innovation rate

F2: Residence time

F3: Product residual value

F4: Obsolescence

\section{Process-related factors}

Implementation of remanufacturing involves not only the technology in the production phase, of the new product, but it goes beyond the manufacturing process. After a used mobile phone is collected, it needs to go through five stages (Steinhilper [33], Tanoto et al. [34]) which are disassembly, cleaning, inspection and sorting, recondition, and reassembly. The technology needed to perform these stages sometimes are not the same as technology used in the production stage. The absence of remanufacturing technology can be a barrier to remanufacturing implementation (Ravi and Shankar [35]), and consequently the availability of advanced remanufacturing technology would be an enabler (Chakraborty et al. [31]). Remanufacturing cost is an important issue in remanufacturing (Franke et al. [8], Lund and Hauser [36], Souza [37]) which is one of the important aspect in making decision to enter 
Table 1. Summary of decision criteria for remanufacturability of mobile phone

\begin{tabular}{|c|c|c|c|}
\hline Category & Decision Criterion & Description & Reference \\
\hline \multirow{4}{*}{$\begin{array}{l}\text { Product } \\
\text { Characteristic }\end{array}$} & F1: Innovation rate & $\begin{array}{l}\text { Rapid innovation in mobile phone makes } \\
\text { remanufacturing more challenging because the } \\
\text { technology might change }\end{array}$ & [4][27] \\
\hline & F2: Residence time & $\begin{array}{l}\text { The longer the of residence time reflected the lower } \\
\text { value of a short life-cycle product }\end{array}$ & {$[23][29]$} \\
\hline & F3: Product residual value & $\begin{array}{l}\text { Product with higher residual value has higher } \\
\text { potential for remanufacturing }\end{array}$ & {$[8][30][31]$} \\
\hline & F4: Obsolescence & $\begin{array}{l}\text { When product becomes obsolete quickly, } \\
\text { remanufacturing becomes less viable }\end{array}$ & {$[14][18][22][32]$} \\
\hline \multirow{3}{*}{$\begin{array}{l}\text { Process-related } \\
\text { factors }\end{array}$} & $\begin{array}{l}\text { F5: Remanufacturing } \\
\text { technology }\end{array}$ & $\begin{array}{l}\text { Availability of remanufacturing technology } \\
\text { increases remanufacturing potential }\end{array}$ & {$[31][33][34][35]$} \\
\hline & F6: Remanufacturing cost & $\begin{array}{l}\text { Remanufacturing potential increases when } \\
\text { remanufacturing cost is within acceptable range }\end{array}$ & {$[4][8][36][37][38]$} \\
\hline & F7: Reverse flow structure & $\begin{array}{l}\text { Availability of reverse flow structure (or whether it } \\
\text { is easy to develop) increases the viability of } \\
\text { remanufacturing }\end{array}$ & {$[38][39][40]$} \\
\hline \multirow{2}{*}{$\begin{array}{l}\text { Supply-related } \\
\text { factors }\end{array}$} & F8: Source of returns & $\begin{array}{l}\text { Remanufacturability is higher when returns are } \\
\text { sufficiently available, quantitatively and } \\
\text { qualitatively }\end{array}$ & [13][39][41] \\
\hline & $\begin{array}{l}\text { F9: Acquisition of used } \\
\text { products }\end{array}$ & $\begin{array}{l}\text { Remanufacturing is more viable when used product } \\
\text { is easy to obtain }\end{array}$ & {$[18][31][41]$} \\
\hline \multirow{4}{*}{$\begin{array}{l}\text { Demand-related } \\
\text { factors }\end{array}$} & F10: Market size & $\begin{array}{l}\text { Successful remanufacturing depends on the } \\
\text { availability of demand with sufficient size }\end{array}$ & $\begin{array}{c}{[4][10][15][37]} \\
{[40][42][43]}\end{array}$ \\
\hline & F11: Market channel & $\begin{array}{l}\text { Remanufactured product needs to be offered via } \\
\text { different channel }\end{array}$ & {$[4][16][17][37]$} \\
\hline & F12: Pricing & $\begin{array}{l}\text { Pricing decision that is attractive and feasible could } \\
\text { increase remanufacturing viability }\end{array}$ & $\begin{array}{c}{[4][15][26][29]} \\
{[37][44][45][46][47][48}\end{array}$ \\
\hline & F13: Green segment & $\begin{array}{l}\text { Existence of green segment supports } \\
\text { remanufacturability }\end{array}$ & {$[16][46][49]$} \\
\hline
\end{tabular}

remanufacturing (Ferguson and Souza [4]). It also be a driver of change because disposal and material cost could be quite large for firms up in the value chain and remanufacturing cost could be lower (Ayres et al. [38]). Successful remanufacturing operations are also influenced by the reverse flow structure that involves the quality, timing, and quantity of returns (Lebreton [39]), as well as the right acquisition price (Vasudevan et al. [40]). Also, sufficient reverse flow are needed in terms of type of agreement between customer and manufacturer, environment legislation, cultural factors, and manufacturer's incentives (Ayres et al. [38]). Therefore, the following factors are included in this study, i.e.

F5: Remanufacturing technology

F6: Remanufacturing cost

F7: Reverse flow structure

\section{Supply-related factors}

Product return or core is the main raw material in remanufacturing process, and it also plays an important role in successful remanufacturing. The availability of returns and their known quality are significant to remanufacturing (van Wassenhove and Zikopoulos [13]), and can be guaranteed by means of leasing program as well as by developing a supply planning (Lebreton [39]). In the reverse flow, there are two approaches found i.e. waste stream and market-driven stream (Guide and van Wassenhove [41]). Under the waste stream, manufacturer is passively receive returns and unable to control the quality. On the other hand, under the market-driven stream, manufacturer offers financial incentives to customers provided a certain quality level of used product. The latter approach has better potential to support remanufacturing practices because the quality of returns is more controllable. Acquisition of used product is affecting the supply of cores for remanufacturing operations. There are several issues in acquisition i.e. uncertainty in quality and quantity of used product (Gurita [18]), and uncertainty in acquisition time (Chakraborty et al. [31]). Optimal acquisition price is needed to make sure sufficient supply and profitability (Guide and van Wassenhove [41]). Therefore, we propose the following factors:

F8: Source of returns

F9: Acquisition of used products

\section{Demand-related factors}

Remanufactured product can be perceived to have lower quality and be inferior compared to new product, and therefore customers' willingness to pay is lower (Souza [37], Agrawal et al.[42]), and it also applied to mobile phone (Neto and Bloemhof [15]). Before manufacturer decides to engage in remanu- 
facturing, there are several significant considerations, which are market size (Rathore et al.[10], Thierry et al. [43]), market channel, and pricing (Ferguson and Souza [4], Souza [37]). Remanufacturing strategies are also determined by market demand of remanufactured product and availability of used product (Vasudevan [40]). The presence of market channel designated for remanufactured product is also important for remanufacturing implementation (Phantratanamongkol et al. [17], Lebreton [39]) because typically high-end customers would not be interested in remanufactured product but instead low-end customers are keen to buy this product at affordable price (Gan et al. [26], Debo et al. [29], Gan et al. [44]). The marketing of remanufactured product is also determined by pricing decision (Neto and Bloemhof [15]), as it could expand the market size and maximize profit (Guide et al.[45], Atasu et al. [46], Ovchinnikov [47], Qiaolun et al. [48]). Furthermore, the existence of green segment could also influence remanufacturability (Mugge et al. [16]) as this segment provides a significant marketing opportunity (Atasu et al. [46], Subramanian et al. [49]). There are four factors extracted from the above discussion:

F10: Market size

F11: Market channel

F12: Pricing

F13: Green segment

\section{Decision-Making Trial and Evaluation Labora- tory (DEMATEL) Method}

The Geneva Research Centre of the Battelle Memorial Institute was the first that developed Decision making trial and evaluation laboratory (DEMATEL) technique. The purpose was to visualize and analyze the structure of cause and effect relationships among several factors in a system. This technique can be implemented to find interdependence among factors and further develop an impact-relation map that shows relative relationships within the factors. It can be used for studying and solving complex and intertwined problems. Furthermore, it finds the prominent factors of a complex structure system based on the impact-relation diagram (Si et al. [50], Falatoonitoosi et al. [51]).

There are four formulating steps for implementing DEMATEL

Construct the direct-relation matrix (DRM) from $n$ factors $\left\{F_{1}, F_{2}, \ldots, F_{n}\right\}$ in a system and $m$ experts $\left\{E_{1}, E_{2}, \ldots, E_{m}\right\}$ in the decision group who are asked to determine the direct influence of $F_{i}$ towards $F_{j}$ using integer scale. For example, using 5 points with " 0 " for no influence, " 1 " for low influence, " 2 " for medium influence, " 3 " for high influence, and finally "4" for very high influence. Then the individual DRM is formed for each expert, $Z_{k}=\left[z_{i j}^{k}\right]_{n \times n}$, where $z_{i j}^{k}$ represents $k^{\text {th }}$ expert's judgment regarding the level of influence $F_{i}$ towards $F_{j}$. By combining $m$ experts decisions, the group DRM can be obtained by

$z_{i j}=\frac{1}{m} \sum_{k=1}^{m} z_{i j}^{k} \quad ; \quad i, j=1,2, \ldots, n$

Normalize DRM to obtain $X$, i.e. normalized group DRM

$X=\frac{Z}{s}$

where

$s=\max \left(\max _{1 \leq i \leq n} \sum_{j=1}^{n} z_{i j}, \max _{1 \leq j \leq n} \sum_{i=1}^{n} z_{i j}\right)$

Generate the total-relation-matrix (TRM) $T=$ $\left[t_{i j}\right]_{n \times n}$, using the normalized DRM by aggregating the direct and indirect effects as follows

$T=X+X^{2}+X^{3}+\cdots+X^{h}=X(I-X)^{-1}$ when $h \rightarrow \infty$

Develop the influential-relation map (IRM) from vectors $R$ and $C$, vectors that consist of sum of rows and columns of matrix $\mathrm{T}$, respectively, i.e.

$R=\left[r_{i}\right]_{n \times 1}=\left[\sum_{j=1}^{n} t_{i j}\right]_{n \times 1}$

$C=\left[c_{j}\right]_{1 \times m}=\left[\sum_{i=1}^{n} t_{i j}\right]_{1 \times n}$

Hence, $\left[r_{i}\right]_{n \times 1}$ is the total effect, which is the sum of the direct and indirect effects, conveyed by factor $F_{i}$ to other factors. Similarly, $\left[c_{j}\right]_{1 \times m}$ is the total effect that factor $F_{j}$ received from other factors. When $i=$ $j$, and $i, j \in\{1,2, \ldots, n\}$, the vector $(R+C)$ demonstrates the degree of importance of a factor in the system. It shows the intensity of the effect dispatched and received by that factor. This is called "Prominence", which plays an important role in the decision-making process. The relative effect of a factor shown by $(R-C)$ is called "Relation", and this is the net effect of a factor contributed to the system. Positive net effect $\left(r_{i}-c_{i}\right)$ represents an active influence given by factor $F_{i}$ to others, while negative net effect shows that $F_{i}$ is receiving influence from other factors. Factors with positive relation is gathered into cause group, while the other into effect group. Furthermore, the dataset $(R+C, R-C)$ is mapped to produce IRM.

\section{Case Illustration}

The analysis of remanufacturability of a mobile phone is done based on decision criteria or factors extracted from literature study as shown in section A. These factors are then discussed with experts from mobile phone manufacturing firms and confirmed as the influencing factors. For analyzing cause effects of these factors by means of DEMATEL, experts are needed to judge the direct relationship among factors. 
Table 2. Direct-relation-matrix of Expert 1

\begin{tabular}{cccccccccccccc}
\hline Criteria & F1 & F2 & F3 & F4 & F5 & F6 & F7 & F8 & F9 & F10 & F11 & F12 & F13 \\
\hline F1 & 0 & 3 & 3 & 4 & 4 & 3 & 1 & 3 & 2 & 3 & 2 & 3 & 3 \\
F2 & 0 & 0 & 4 & 3 & 0 & 1 & 2 & 4 & 4 & 3 & 0 & 2 & 0 \\
F3 & 1 & 3 & 0 & 2 & 0 & 2 & 0 & 4 & 4 & 0 & 0 & 3 & 0 \\
F4 & 2 & 4 & 4 & 0 & 3 & 2 & 1 & 3 & 3 & 2 & 1 & 2 & 2 \\
F5 & 3 & 0 & 0 & 1 & 0 & 4 & 0 & 0 & 0 & 3 & 0 & 3 & 1 \\
F6 & 0 & 0 & 0 & 0 & 0 & 0 & 0 & 0 & 0 & 1 & 0 & 4 & 2 \\
F7 & 0 & 0 & 2 & 0 & 0 & 4 & 0 & 3 & 4 & 0 & 0 & 4 & 2 \\
F8 & 0 & 0 & 1 & 0 & 0 & 3 & 3 & 0 & 3 & 0 & 0 & 3 & 1 \\
F9 & 0 & 4 & 3 & 1 & 0 & 3 & 3 & 4 & 0 & 1 & 2 & 3 & 2 \\
F10 & 4 & 3 & 2 & 2 & 3 & 1 & 3 & 3 & 3 & 0 & 4 & 4 & 2 \\
F11 & 0 & 1 & 1 & 0 & 0 & 0 & 3 & 1 & 1 & 3 & 0 & 4 & 4 \\
F12 & 1 & 1 & 1 & 0 & 0 & 0 & 1 & 1 & 1 & 4 & 3 & 0 & 3 \\
F13 & 2 & 2 & 0 & 0 & 0 & 0 & 1 & 3 & 3 & 4 & 4 & 4 & 0 \\
\hline \multicolumn{7}{c}{$0=$ no influence, 1=low influence, $2=$ medium influence, 3=high influence, 4=very high influence }
\end{tabular}

Table 3. Direct-relation-matrix of Expert 2

\begin{tabular}{cccccccccccccc}
\hline Criteria & F1 & F2 & F3 & F4 & F5 & F6 & F7 & F8 & F9 & F10 & F11 & F12 & F13 \\
\hline F1 & 0 & 2 & 1 & 3 & 3 & 2 & 1 & 3 & 1 & 4 & 2 & 4 & 2 \\
F2 & 0 & 0 & 4 & 1 & 0 & 0 & 1 & 4 & 4 & 3 & 0 & 1 & 0 \\
F3 & 0 & 4 & 0 & 1 & 0 & 3 & 0 & 4 & 4 & 0 & 0 & 3 & 0 \\
F4 & 2 & 4 & 3 & 0 & 3 & 2 & 1 & 3 & 2 & 2 & 1 & 2 & 1 \\
F5 & 3 & 0 & 1 & 1 & 0 & 4 & 0 & 0 & 1 & 2 & 0 & 3 & 0 \\
F6 & 0 & 0 & 0 & 0 & 0 & 0 & 0 & 0 & 0 & 1 & 0 & 4 & 2 \\
F7 & 0 & 0 & 1 & 0 & 0 & 4 & 0 & 3 & 4 & 0 & 0 & 3 & 1 \\
F8 & 0 & 0 & 1 & 0 & 0 & 4 & 3 & 0 & 3 & 0 & 0 & 2 & 0 \\
F9 & 0 & 4 & 3 & 1 & 0 & 3 & 3 & 4 & 0 & 1 & 2 & 3 & 0 \\
F10 & 4 & 3 & 2 & 2 & 2 & 1 & 3 & 3 & 3 & 0 & 4 & 4 & 2 \\
F11 & 0 & 0 & 0 & 0 & 0 & 0 & 2 & 1 & 1 & 4 & 0 & 4 & 3 \\
F12 & 0 & 1 & 0 & 0 & 0 & 0 & 0 & 0 & 0 & 4 & 4 & 0 & 4 \\
F13 & 1 & 3 & 0 & 0 & 0 & 0 & 0 & 4 & 4 & 4 & 4 & 4 & 0 \\
\hline
\end{tabular}

$0=$ no influence, $1=$ low influence, $2=$ medium influence, $3=$ high influence, $4=$ =very high influence

Experts could be academic members or practitioners who have significant working experience and expertise in mobile phone manufacturing, or reverse logistics, or technical aspects of remanufacturing, or managerial aspects of refurbished/ remanufacturing mobile phone. Since mobile phone remanufacturing has not been implemented in Indonesia, it is very difficult to such experts. To illustrate the decisionmaking process, we use an example where three experts involved. The number of experts is limited to small size because there are limited mobile phone manufacturers and remanufacturing practitioners, hence very limited chance to get potential experts. Bhatia and Srivastava [22] and Lee et al. [52] show that DEMATEL approach can be implemented with limited number of experts, like three experts in [22] that provided robust results and not very dependent on number of experts. In this case illustration, there are three experts with different characteristics, reflected in the individual DRM, which are optimistic to remanufacturability of mobile phone, extreme in giving evaluation, and being indifferent. After obtaining DRM that shows the interrelationships among factors, we proceed with the DEMATEL approach described in section B to develop IRM. The analysis of IRM provides four quadrants to show core factors or intertwined givers, driving factors or autonomous givers, independent factors or autonomous receivers, and impact factors or intertwined receivers (Si et al.[50]). Managerial insights are then provided based on these results to understand the interrelationships among factors and prominent factors in mobile phone remanufacturing. An influential-relation map is provided to visualize the causal effect relations.

\section{Results and Discussions}

Direct relation matrix is prepared using 5 point scale $0-4$ where " 0 " = no influence, " 1 " = low influence, " $2 "=$ medium influence, " $3 "=$ high influence, and finally " $4 "=$ very high influence. This case uses illustration of three experts to show relationships among 13 factors as decision criteria for remanufacturability of mobile phone. Table 2-4 shows the responses of each expert, Table 5 shows the total-relation matrix.

The aggregated effect pair values for each decision criteria as shown in Table 6 are mapped to "Prominence", i.e. $(R+C)$, as the horizontal axis, and "Relation", i.e. $(R-C)$, as the vertical axis. The 
Table 4. Direct-relation-matrix of Expert 3

\begin{tabular}{cccccccccccccc}
\hline Criteria & F1 & F2 & F3 & F4 & F5 & F6 & F7 & F8 & F9 & F10 & F11 & F12 & F13 \\
\hline F1 & 0 & 1 & 2 & 4 & 3 & 3 & 1 & 2 & 2 & 2 & 2 & 2 & 2 \\
F2 & 0 & 0 & 3 & 4 & 0 & 1 & 1 & 3 & 3 & 3 & 0 & 1 & 0 \\
F3 & 1 & 3 & 0 & 2 & 0 & 2 & 0 & 4 & 4 & 0 & 0 & 3 & 0 \\
F4 & 1 & 3 & 4 & 0 & 2 & 2 & 1 & 4 & 3 & 2 & 1 & 1 & 2 \\
F5 & 2 & 0 & 0 & 0 & 0 & 4 & 0 & 0 & 0 & 3 & 0 & 4 & 1 \\
F6 & 0 & 0 & 0 & 0 & 0 & 0 & 0 & 0 & 0 & 1 & 0 & 3 & 2 \\
F7 & 0 & 0 & 1 & 0 & 0 & 4 & 0 & 3 & 4 & 0 & 0 & 3 & 1 \\
F8 & 0 & 0 & 1 & 0 & 0 & 3 & 3 & 0 & 3 & 0 & 0 & 4 & 0 \\
F9 & 0 & 3 & 4 & 1 & 0 & 2 & 3 & 4 & 0 & 1 & 2 & 3 & 1 \\
F10 & 3 & 4 & 1 & 1 & 3 & 1 & 3 & 3 & 3 & 0 & 4 & 4 & 3 \\
F11 & 0 & 1 & 0 & 0 & 0 & 0 & 2 & 1 & 1 & 3 & 0 & 4 & 4 \\
F12 & 1 & 3 & 3 & 0 & 0 & 0 & 2 & 2 & 2 & 4 & 3 & 0 & 3 \\
F13 & 1 & 3 & 1 & 1 & 0 & 0 & 1 & 3 & 3 & 3 & 3 & 3 \\
\hline \multicolumn{7}{c}{ 0=no influence, 1=low influence, $2=$ medium influence, 3=high influence, 4=very high influence } \\
\hline
\end{tabular}

Table 5. Total-relation-matrix

\begin{tabular}{cccccccccccccc}
\hline Criteria & F1 & F2 & F3 & F4 & F5 & F6 & F7 & F8 & F9 & F10 & F11 & F12 & F13 \\
\hline F1 & 0.04 & 0.13 & 0.12 & 0.13 & 0.12 & 0.14 & 0.09 & 0.17 & 0.14 & 0.16 & 0.12 & 0.21 & 0.13 \\
F2 & 0.02 & 0.06 & 0.15 & 0.10 & 0.02 & 0.08 & 0.09 & 0.18 & 0.17 & 0.12 & 0.04 & 0.12 & 0.04 \\
F3 & 0.03 & 0.13 & 0.05 & 0.07 & 0.01 & 0.11 & 0.05 & 0.17 & 0.16 & 0.05 & 0.04 & 0.15 & 0.04 \\
F4 & 0.07 & 0.16 & 0.16 & 0.04 & 0.09 & 0.13 & 0.09 & 0.18 & 0.16 & 0.12 & 0.08 & 0.16 & 0.10 \\
F5 & 0.09 & 0.04 & 0.04 & 0.04 & 0.02 & 0.14 & 0.03 & 0.05 & 0.05 & 0.12 & 0.04 & 0.15 & 0.06 \\
F6 & 0.01 & 0.02 & 0.01 & 0.01 & 0.01 & 0.01 & 0.02 & 0.02 & 0.02 & 0.05 & 0.03 & 0.13 & 0.07 \\
F7 & 0.01 & 0.04 & 0.07 & 0.01 & 0.00 & 0.14 & 0.04 & 0.13 & 0.15 & 0.04 & 0.03 & 0.15 & 0.07 \\
F8 & 0.01 & 0.03 & 0.05 & 0.01 & 0.00 & 0.12 & 0.10 & 0.04 & 0.12 & 0.03 & 0.03 & 0.13 & 0.04 \\
F9 & 0.02 & 0.15 & 0.14 & 0.05 & 0.01 & 0.13 & 0.13 & 0.19 & 0.09 & 0.09 & 0.09 & 0.18 & 0.08 \\
F10 & 0.13 & 0.17 & 0.12 & 0.09 & 0.10 & 0.11 & 0.15 & 0.19 & 0.19 & 0.10 & 0.18 & 0.25 & 0.14 \\
F11 & 0.03 & 0.07 & 0.05 & 0.02 & 0.01 & 0.04 & 0.10 & 0.09 & 0.09 & 0.14 & 0.05 & 0.18 & 0.14 \\
F12 & 0.04 & 0.10 & 0.08 & 0.03 & 0.02 & 0.04 & 0.07 & 0.10 & 0.10 & 0.16 & 0.14 & 0.09 & 0.13 \\
F13 & 0.06 & 0.13 & 0.07 & 0.04 & 0.02 & 0.06 & 0.08 & 0.17 & 0.17 & 0.17 & 0.15 & 0.20 & 0.06 \\
\hline
\end{tabular}

diagram is divided into four quadrants (see Figure 1 ), based on mean value of $(R+C)$, which is 2.33 , as the vertical divisor, and mean value of $(R-C)$, which is 0 , as the horizontal divisor. Each pair values of decision criteria will fall into one of the quadrant and the overall plot provides a visualization of causal relationship among factors and assists decision makers in identifying the important factors for further actions.

Figure 1 shows the influential-relation map with prominence causal relationship as the result of tablerelation-matrix (Table 5) and prominence-relation values (Table 6). It shows that innovation rate $(\mathrm{F} 1)$, obsolescence (F4), market size (F10), remanufacturing technology (F5), and green segment (F13) are in causal group since $(R-C)>0$. They impact other factors and therefore should be given considerable attention. The highest impacts are innovation rate (F1) and obsolescence (F4). This is understandable since mobile phone is a short lifecycle product that is sensitive to rapid change in technology. Customers might have concerns with remanufactured mobile phone as they might get obsolete quickly and the new generation or new models is emerging in the market, hence could influence the quantity of demand. Therefore, managers of manufacturing firm should select carefully which product that is suitable for remanufacturing. For example, high-end mobile phone with prominent brand could be interesting because the remanufactured product price will be more affordable. On the other hand, reverse flow structure (F7), acquisition of used product (F9), remanufacturing cost (F6), source of returns (F8), and pricing (F12) are in effect group with negative $(R-C)$. They are influenced by other factors and could indirectly improve the system when their causal factors are improved.

Observing prominence value from Table 6, the results show that acquisition of used product (F9), pricing (F12), and market size (F10) are dominant factors as they significantly affect and affected by others. This is consistent with Bhatia [22] where acquisition of used product is one of the most prominent barrier. Therefore, managers need to take immediate actions to treat these factors in order to improve remanufacturability of mobile phone. Managers could adopt market-driven stream (Guide and van Wassenhove [41]) with interesting acquisition price to attract consumers in returning used product with determined quality level. Pricing decision is also a central criterion, which is shown by 
Table 6. Prominence-relation for each decision criteria

\begin{tabular}{lcccc}
\hline \multicolumn{1}{c}{ Criteria } & $\mathrm{R}$ & $\mathrm{C}$ & $\mathrm{R}+\mathrm{C}$ & $\mathrm{R}-\mathrm{C}$ \\
\hline F1: Innovation rate & 1.70 & 0.58 & 2.28 & 1.12 \\
F2: Residence time & 1.20 & 1.24 & 2.43 & -0.04 \\
F3: Product residual value & 1.06 & 1.12 & 2.18 & -0.06 \\
F4: Obsolescence & 1.54 & 0.63 & 2.18 & 0.91 \\
F5: Remanufacturing & & & & \\
technology & 0.88 & 0.43 & 1.31 & 0.45 \\
F6: Remanufacturing cost & 0.42 & 1.24 & 1.66 & -0.83 \\
F7: Reverse flow structure & 0.89 & 1.04 & 1.93 & -0.14 \\
F8: Source of returns & 0.72 & 1.68 & 2.40 & -0.96 \\
F9: Acquisition of used products & 1.34 & 1.61 & 2.95 & -0.27 \\
F10: Market size & 1.92 & 1.36 & 3.28 & 0.56 \\
F11: Market channel & 1.01 & 1.01 & 2.03 & 0.00 \\
F12: Pricing & 1.10 & 2.10 & 3.20 & -1.00 \\
F13: Green segment & 1.39 & 1.12 & 2.51 & 0.28 \\
\hline
\end{tabular}

Influential-Relation Map (IRM)

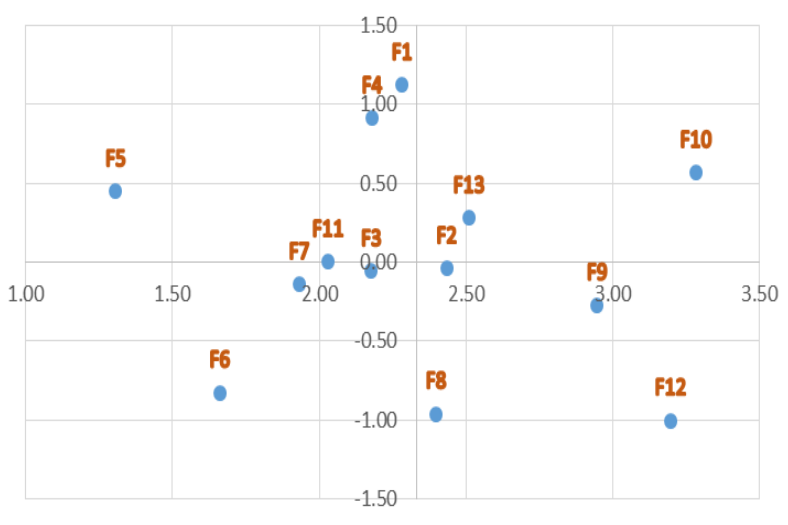

Figure 1. Prominence causal-effect diagram

vast range of research, relevant to remanufacturability of mobile phone. Managers need to decide optimal price for remanufactured product to maximize profit. Market size is the most prominent factor, since it affects many other factors. Managers should take actions to increase market size, such as educating customers to appreciate the benefits of using remanufactured product to the environment and society (Wahjudi et al.[53]), promoting the quality of remanufactured product by means of warranty (Gan and Pujawan [54]).

Figure 1 also shows that market size (F10) and green segment (F13) are in the first quadrant which means they are core factors or intertwined givers. Market size (F10) is the most important as it influence others and highly related to other factors, and therefore should be given the utmost attention by managers. Innovation rate (F1), obsolescence (F4), and remanufacturing technology (F5) are located in the second quadrant i.e. driving factors or autonomous givers as they have low prominence by high relation. Chaowanapong [20] also found that product maturity which is characterized by the speed of technological innovation and product's life. Remanufacturing cost (F6) and reverse flow structure (F7) are in third quadrant, which shows that they are relatively detached from the system with low prominence and low relation with other factors. Source of return (F8) and pricing (F12) are placed in fourth quadrant which are called impact factors or intertwined receivers. They have high prominence but easily influenced by other factors. Therefore, these factors should not be treated individually but rather in conjunction with the affecting factors.

\section{Conclusion}

This paper studies factors that affecting remanufacturability of mobile phone. The decision criteria are determined from literature study. There are thirteen criteria extracted from the literature, and categorized into four groups i.e. product characteristics, process-related factors, supply-related factors, and demand-related factors. The analysis is done by applying DEMATEL approach. We use case illustration with three experts with three different characteristics i.e. optimistic, extreme, and indifferent. The results show which factors are in causal group and in effect group. Also, the prominence factors are identified and followed by relevant managerial insights. Furthermore, the factors are plotted into influential-relation map with four quadrants to show which ones are core factors, driving factors, detached from the system, and impact factors. From this map, managers could take relevant actions accordingly.

There are limitations to this study. First, mobile phone remanufacturing is not found in Indonesia. There are refurbished mobile phones sold here but they are imported from other countries such as Singapore and Korea, not remanufactured in Indonesia. Further study can be carried out by doing joint research with researcher from other country where mobile phone remanufacturing is implemented, such as United States of America, Japan, and China. The research partner can provide access to experts with experience and expertise in mobile phone remanufacturing. Second, in this study, the expert evaluation is considered deterministic even though in reality they are quite uncertain. Therefore, future research can be extended to use fuzzy DEMATEL which accommodates this uncertainty.

\section{References}

1. E-Marketer Inc., 2 Billion Consumers Worldwide to Get Smart (phones) by 2016, web-page, 2014. Available: https://www.emarketer.com/ Articles/Print.aspx?R=1011694.

2. van Weelden, E., Mugge, R., and Bakker, C., Paving the Way towards Circular Consumption: Exploring Consumer Acceptance of Refurbished Mobile Phones in the Dutch Market, Journal of Cleaner Prodution, 113, 2016, pp. 743-754. 
3. Goodall, P., Rosamond, E., and Harding, J., A Review of the State of the Art in Tools and Techniques used to Evaluate Remanufacturing Feasibility, Journal of Cleaner Production, 81, 2014, pp. 1-15.

4. Ferguson, M. E. and Souza, G. C., Closed-loop Supply Chains - New Developments to Improve the Sustainability of Business Practices. CRC Press, Taylor \& Francis Group, 2010.

5. Lebreton, B., and Tuma, A., A Quantitative Approach to Assessing the Profitability of Car and Truck Tire Remanufacturing, International Journal of Production Economics, 104, 2006, pp. 639-652.

6. Charter, M., and Gray, C., Remanufacturing and Product Design, International Journal of Product Development, 6(3-4), 2008, pp. 375-392.

7. Östlin, J., Sundin, E., and Björkman, M., Product Life-cycle Implications for Remanufacturing Strategies, Journal of Cleaner Production, 17(11), 2009, pp. 999-1009.

8. Franke, C., Basdere, B., Ciupek, M., and Seliger, S., Remanufacturing of Mobile Phones - capacity, Program and Facility Adaptation Planning, Omega, 34(6), 2006, pp. 562-570.

9. Tong, B., Research on the Cell Phone Remanufacturing and Reselling, Doctoral dissertation, Erasmus University, 2006.

10. Rathore, P., Kota, S., and Chakrabarti, A., Sustainability through Remanufacturing in India: A Case Study on Mobile Handsets, Journal of Cleaner Production, 19(15), 2011, pp. 17091722.

11. Xing, K., Belusko, M., Luong, L., and Abhary, K., An Evaluation Model of Product Upgradeability for Remanufacture, International Journal of Advance Manufacturing Technology, 35(1-2), 2007, pp. 1-14.

12. Kwak, M. and Kim, H., Design for Life-cycle Profit with Simultaneous Consideration of Initial Manufacturing and End-of-life Remanufacturing, Engineering Optimization, 47(1), 2015, pp. 18-35.

13. van Wassenhove, L. N. and Zikopoulos, C., On the Effect of Quality Overestimation in Remanufacturing, International Journal of Production Research, 48(18), 2010, pp. 5263-5280.

14. Nnorom, I. C., and Osibanjo, O., Overview of Prospects in Adopting Remanufacturing of Endof-Life Electronic Products in the Developing Countries, International Journal of Innovation Management Technology, 1(3), 2010, p. 328.

15. Quariguasi-Frota-Neto, J., and Bloemhof, J., An Analysis of the Eco-efficiency of Remanufactured Personal Computers and Mobile Phones, Production and Operations Management, 21(1), 2012, pp. 101-114.
16. Mugge, R., Jockin, B., and Bocken, N., How to Sell Refurbished Smartphones? An Investigation of Different Customer Groups and Appropriate Incentives, Journal of Cleaner Production, 147, 2017,pp. 284-296.

17. Phantratanamongkol, S., Casalin, F., Pang, G., and Sanderson, J., The Price-volume Relationship for New and Remanufactured Smartphones, International Journal of Production Economic, 199, 2018, pp. 78-94.

18. Gurita, N., Fröhling, M., and Bongaerts, J., Assessing Potentials for Mobile/Smartphone Reuse/Remanufacture and Recycling in Germany for a Closed Loop of Secondary Precious and Critical Metals, Journal of Remanufacturing, 8 (1-2), 2018, 1-22

19. D’Adamo, I., and Rosa, P., Remanufacturing in Industry: Advices from the Field, International Journal of Advance Manufacturing Technology, 86(9-12), 2016,pp. 2575-2584.

20. Chaowanapong, J., Jongwanich, J., and Ijomah, W., Factors Influencing a Firm's Decision to Conduct Remanufacturing: Evidence from the Thai Automotive Parts Industry, Production Planning and Control, 28(14), 2017, pp. 11391151.

21. Xia, X., Govindan, K., and Zhu, Q., Analyzing Internal Barriers for Automotive Parts Remanufacturers in China using Grey-DEMATEL Approach, Journal of Cleaner Production, 87, 2015, pp. 811-825.

22. Bhatia, M. S., and Srivastava, R. K., Analysis of External Barriers to Remanufacturing using Grey-DEMATEL Approach : An Indian Perspective, Resources, Conservation and Recycling, 136, 2018, pp. 79-87.

23. Sharma, V., Garg, S. K., and Sharma, P. B., Identification of Major Drivers and Roadblocks for Remanufacturing in India, Journal of Cleaner Production, 112, 2016, pp. 1882-1892.

24. Wei, S., Cheng, D., Sundin, E., and Tang, O., Motives and Barriers of the Remanufacturing Industry in China, Journal of Cleaner Production, 94, 2015, pp. 340-351.

25. Gan, S.-S., Pujawan, I. N., Suparno, and Widodo, B., Pricing Decision Model for New and Remanufactured Short-life Cycle Products with Time-dependent Demand, Operation Research Perspective, 2, 2015, pp. 1-12.

26. Gan, S.-S., Pujawan, I. N., and Suparno, Remanufacturing of Short Life-cycle Products, Operation Supply Chain Management, 7(1), 2014, pp. 13-22.

27. Souza, G. C., Remanufacturing in Closed-Loop Supply Chains, 45(1), 2009, pp. 56-66.

28. Debo, L. G., Toktay, L. B., and van Wassenhove, L. N., Joint Life-cycle Dynamics of New and Remanufactured Products, Production and Operations Management, 15(4), 2006, pp. 498-513. 
29. Debo, L. G., Toktay, L. B., and van Wassenhove, L. N., Market Segmentation and Product Technology Selection for Remanufacturable Products, Management Science, 51(8), 2013, pp. 1193-1205.

30. Gobbi, C., Designing the Reverse Supply Chain : The Impact of the Product Residual Value, International Journal of Physical Distribution \& Logistics Management, 41(8), 2011, pp. 768-796.

31. Chakraborty, K., Mondal, S., and Mukherjee, K., Critical Analysis of Enablers and Barriers in Extension of Useful Life of Automotive Products through Remanufacturing, Journal of Cleaner Production, 227, 2019, pp. 1117-1135.

32. Deshpande, A., Chouksey, P., and Babu, A. S., Identification and Analysis of Customer's Requirements from Refurbished Electronics in Order to Create Customer Value, In Advances in Data and Information Sciences. Springer, Singapore, 2019, pp. 223-243.

33. Steinhilper, R., Remanufacturing - The Ultimate Form of Recycling, Fraunhofer IRB Verlag, 1998.

34. Tanoto, Y. Y., Gan, S.-S, Wahjudi, D. and Anggono, J., A Preliminary Study of Technical Feasibility for Mobile Phone Remanufacturing in Indonesia, Journal of Telecommunication, Electronic and Computer Engineering, 10(2), 2018, pp. 117-121.

35. Ravi, V., and Shankar, R., Analysis of Interactions among the Barriers of Reverse Logistics, Technological Forecasting and Social Change, 72(8), 2005, pp. 1011-1029.

36. Lund, R. T., and Hauser, W. M., Remanufacturing - An American Perspective, in 5th International Conference on Responsive Manufacturing - Green Manufacturing (ICRM 2010), Ningbo, China, 11-13 January 2010., 2010, pp. 1-6.

37. Souza, G. C., Remanufacturing in Closed-Loop Supply Chains, Production and Inventory Management Journal, 45(1), 2009, pp. 56-66.

38. Ayres, R. U., Ferrer, G., and van Leynseele, T., Eco-efficiency, Asset Recovery and Remanufacturing, European Management Journal, 15(5), 1997, pp. 557-574.

39. Lebreton, B., Strategic Closed-Loop Supply Chain Management, in Lecture Notes in Economics and Mathematical Systems 586, Springer Berlin Heidelberg, 2007, pp. 1-158.

40. Vasudevan, H., Kalamkar, V., and Terkar, R., Remanufacturing for Sustainable Development: Key Challenges, Elements, and Benefits, International Journal of Innovation, Management and Technology, 3(1), 2012, pp. 84-89.

41. Guide, V. D. R. J., and van Wassenhove, L. N., Managing Product Returns for Remanufacturing, Production and Operations Management, 10(2), 2001, pp. 142-155.
42. Agrawal, V. V., Atasu, A., and van Ittersum, K., Remanufacturing, Third-Party Competition, and Consumers' Perceived Value of New Products, Marketing Science, 61(1), 2015, pp. 60-72.

43. Thierry, M., Salomon, M., van Nunen, J. A. E. E., and van Wassenhove, L. N., Strategic Issues in Product Recovery Management, California Management Review, 37(2), 1995, pp. 114-135.

44. Gan, S.-S., Pujawan, I. N., Suparno, and Widodo, B., Pricing Decision for New and Remanufactured Product in a Closed-loop Supply Chain with Separate Sales-channel, Int. J. Prod. Econ., 190, pp. 120-132, 2017.

45. Guide, V. D. R. J., Teunter, R. H., and van Wassenhove, L. N., Matching Demand and Supply to Maximize Profits from Remanufacturing, Manufacturing \& Service Operations Management, 5(4), 2003, pp. 303-316.

46. Atasu, A., Sarvary, M., and van Wassenhove, L. N., Remanufacturing as a Marketing Strategy, Management Science, 54(10), 2008, pp. 17311746.

47. Ovchinnikov, A., Revenue and Cost Management for Remanufactured Products, Production and Operations Management, 20(6), 2011, pp. 824-840.

48. Qiaolun, G., Jianhua, J., and Tiegang, G., Pricing Decisions for Reverse Supply Chains, Kybernetes, 40(5/6), 2011, pp. 831-841.

49. Subramanian, R., Ferguson, M. E., and Beril Toktay, L., Remanufacturing and the component Commonality Decision, Production and Operations Management, 22(1), 2013, pp. 36-53.

50. Si, S., You, X., Liu, H., and Zhang, P., DEMATEL Technique: A Systematic Review of the State-of-the-Art Literature on Methodologies and Applications, Mathematical Problems in Engineering, 2018, 2018, pp. 1-33.

51. Falatoonitoosi, E., Leman, Z., Sorooshian, S., and Salimi, M., Decision-making Trial and Evaluation Laboratory, Research Journal of Applied Sciences, Engineering and Technology, 5(13), 2013, pp. 3476-3480.

52. Lee, H., Tzeng, G., Yeih, W., Wang, Y., and Yang, S., Revised DEMATEL: Resolving the Infeasibility of DEMATEL, Applied Mathematical Modelling, 37(10-11), 2013, pp. 6746-6757.

53. Wahjudi, D., Gan, S.-S., Anggono, J., and Tanoto, Y. Y., Factors Affecting Purchase Intention of Remanufactured Short Life-Cycle Products, in International Conference on Management and Enterpreneurship, 2017.

54. Gan, S.-S., and Pujawan, I. N., Pricing and Warranty Level Decisions for New and Remanufactured Short Life-Cycle Products, Jurnal Teknik Industri, 19(1), 2017, pp. 39-46. 